\title{
A Proposed Selection Index for Jersey Cattle in Zimbabwe
}

\author{
Edward Missanjo, ${ }^{1}$ Venancio Imbayarwo-Chikosi, ${ }^{2}$ and Tinyiko Halimani ${ }^{2}$ \\ ${ }^{1}$ Malawi College of Forestry and Wildlife, Private Bag 6, Dedza, Malawi \\ ${ }^{2}$ Department of Animal Science, Faculty of Agriculture, University of Zimbabwe, P.O. Box MP 167, Mount Pleasant, Harare, Zimbabwe
}

Correspondence should be addressed to Edward Missanjo; edward.em2@gmail.com

Received 5 February 2013; Accepted 28 February 2013

Academic Editors: P. Butaye and J. F. Hocquette

Copyright (C) 2013 Edward Missanjo et al. This is an open access article distributed under the Creative Commons Attribution License, which permits unrestricted use, distribution, and reproduction in any medium, provided the original work is properly cited.

\begin{abstract}
A multitrait selection index $\left(I_{T}\right)$ for Zimbabwean Jersey cattle was constructed. The breeding objective was defined in terms of production and functionality traits. The production component of the index included milk yield $(M)$, butterfat yield $(F)$, protein yield $(P)$, butterfat percent $(F \%)$, and protein percent $(P \%)$, while the functional component included the somatic cell count (SCC). The index was termed as $I_{T}=0.0004 M+0.0109 F+0.0313 P+1.0004 F \%+2.4491 P \%-0.1905 S C C$. The accuracy of the index was $91.1 \%$, and the correlation between this index and the aggregate breeding objective was 0.954 . A selection index is more important in the selection of sires and cows. This leads to the greatest genetic progress and hence productivity in the dairy sector. Therefore, the application of the selection index developed is necessary if the dairy cattle industry is to maximise the exploitation of genetics and to improve its relative competitive position.
\end{abstract}

\section{Introduction}

König and Swalve [1] presented a multiple correlation method of constructing optimum selection indexes. However, to solve the simultaneous equations, the genetic parameters (heritability and genetic correlations) and phenotypic parameters (standard deviation and correlations) among traits must be known. When these traits differ in variability, heritability, and in the correlation among their phenotypes and genotypes, index selection is more effective than independent culling levels or sequential selection [2], and the construction of an index is not easy without the use of matrix methods, particularly, if there are more than two sources of information, and improves as the number of traits in the selection index increases [3].

Dekkers [4] reported that the selection of both production traits (protein yield, protein \%) and functional traits (longevity, milkability, and somatic cell score) increased the selection index efficiency to $58 \%$. Sørensen et al. [5] found that the selection of milk yield, somatic cell score, udder depth, teat placement, and foot angle improved efficiency of response in the aggregate genotype by $1 \%$ to $4 \%$ over selection for milk yield alone. Sun et al. [6] reported that for improving milk yield, selection indices comprising milk, fat, or protein yields were $98 \%-100 \%$ as efficient as an index comprising all three traits. Selection on milk yield alone was $5 \%$ less efficient in improving milk yield compared with the selection using an index of all three traits.

According to [7], every country should develop its selection index because the success of selection index from different countries cannot be compared, even though breeding goals are very similar. For some time in Zimbabwe, the only means of selection of local bulls have been on the basis of pedigree information and visual appraisal, which with no doubt had an adverse on genetic progress. Essentially, two of the most heavily used Zimbabwean bulls at one time had an average predicted difference of $-370 \mathrm{~kg}$ milk [8]. Therefore, the objectives of this study were to develop a multitrait selection index for Jersey cattle in Zimbabwe and to test the accuracy and efficiency of the index. The index would give farmers an option of selecting one or more traits at a time, depending on the farmer's selection goals.

\section{Materials and Methods}

2.1. Environment. Zimbabwe is located in southern Africa in the tropical savannah region. The total land area is 
$390,759 \mathrm{~km}^{2}$ and it is divided into five agroecological regions. Rainfall patterns and crop production progressively deteriorate from Region I to V. However, livestock production including dairying is practised in all the regions. In the regions with low rainfall, dairying is assisted by the production of drought resistant fodder crops. Most dairy farms are located within $40 \mathrm{~km}$ of the major cities and towns [9].

2.2. Data and Data Edits. The standard 305-day milk production records of pure bred Jersey were obtained from Zimbabwe Livestock Identification Trust (LIT). Missanjo [10] described the dataset and the edits. This gave a dataset of 10,986 records with cows calving in the period 1996-2008.

2.3. Statistical Analysis. Multivariate analyses using repeatability animal model and the ASReml program developed by [11] were used. The animal model included fixed effects of herd-year-season, previous calving interval, days dry, linear, and quadratic regression coefficients of age at calving as covariates, permanent environmental, and animal effects. From this, variance components, heritability, predicted breeding values (EBVs), and genetic and phenotypic correlations were estimated. These were then used in the construction of the index. SelAction programme Version 2.1 developed by [12] was used to develop the index.

The index was developed in order to allow breeders to select sires and dams for simultaneous improvement of both production and functionality traits. The production component of the index included milk yield $(M)$, fat yield $(F)$, protein yield $(P)$, fat percent $(F \%)$, and protein percent $(P \%)$, while the functional component included the somatic cell count (SCC).

The selection index constructed was

$$
\mathbf{P b}=G_{12} \mathbf{a} .
$$

The selection index weights were then calculated as

$$
\mathbf{b}=\mathbf{P}^{-1} G_{12} \mathbf{a}
$$

where $G_{12}$ is an $n \times m$ genetic variance-covariance matrix for $m$ traits affecting profitability and $n$ correlated indicator traits (criteria) and incorporates the additive genetic relationships between sources of information; $\mathbf{P}$ is a $n \times n$ phenotypic (co)variance matrix of correlated indicator traits; $\mathbf{b}$ is a vector of index weights (coefficients) for the phenotypic values of the selection criteria (traits); $\mathbf{a}$ is an $n \times 1$ vector which express the relative importance by the breeder to each trait. In this case, as described by [13], an equal change in standard-deviation units was used for each trait. Therefore, the "a" that were assigned to each trait were the reciprocals of the phenotypic standard deviations.

As stated above, the optimum set of the selection index coefficients are those which maximise the correlation $\left(r_{H I}\right)$ or minimise the squared deviation between the selection index and the aggregate genotype (breeding objective). Therefore, according to [14], the accuracy of index selection is a function of the correlation $\left(r_{H I}\right)$ between the aggregate genotype and the index and was calculated as

$$
r_{H I}^{2}=\frac{\boldsymbol{\sigma}_{I}^{2}}{\boldsymbol{\sigma}_{H}^{2}},
$$

where $\boldsymbol{\sigma}_{I}^{2}$ and $\boldsymbol{\sigma}_{H}^{2}$ were the variances of the index and the breeding objective, respectively. These variances were calculated as

$$
\begin{aligned}
& \boldsymbol{\sigma}_{I}^{2}=\mathbf{b}^{\prime} G_{12} \mathbf{a}, \\
& \boldsymbol{\sigma}_{H}^{2}=\mathbf{a}^{\prime} G_{22} \mathbf{a},
\end{aligned}
$$

where a and $G_{12}$ are as described above; $G_{22}$ is the $m \times m$ genetic variance-covariance matrix of the $m$ traits in the breeding objective.

\section{Results and Discussion}

The selection index developed was

$$
\begin{aligned}
I_{T}= & 0.0004 M+0.0109 F+0.0313 P+1.0004 F \% \\
& +2.4491 P \%-0.1905 \text { SCC. }
\end{aligned}
$$

These means that animals can then be ranked according to these index values and selection based on these rankings. The positive signs for production traits and negative sign for functionality trait mean that the index developed will allow breeders to select sires and dams, which will be increasing the production traits and decreasing the functionality trait, respectively.

The use of SCC for selection purposes has been widely discussed because the elevation of SCC with an infection is a clear indication of the occurrence of infection as well as of the immunological response to combat the infection. Recent studies clearly indicate, however, that the genetic correlation with clinical cases of mastitis is reasonably high and that the relationship is linear. Low SCC follows low prevalence of mastitis, and high SCC indicates high prevalence. Thus, the validity of using SCC as an indirect measure to improve mastitis resistance has been strengthened [5].

The variances $\left(\boldsymbol{\sigma}_{I}^{2}\right)$ of this index $\left(I_{T}\right)$ and $\left(\boldsymbol{\sigma}_{H}^{2}\right)$ of the breeding objectives were computed as 12.23 and 13.43, respectively. The accuracy of the index was $91.1 \%$, and the correlation with the objective was 0.954 .

To test the effect of individual criteria on the efficiency of the index $\left(I_{T}\right)$, these criteria were deleted one at a time from the index. The efficiency of these sub-indices was then compared to the efficiency of the overall index. These results are summarized in Table 1.

Table 1 clearly shows that most individual criteria have only a small influence on the efficiency of the index. However, when milk yield, fat yield, or protein yield is dropped from the index, the resultant subindices are only $51.7 \%, 53.3 \%$, or $52.9 \%$ accurate, respectively, compared to the $91.1 \%$ of the total index with these criteria included. Since dropping certain traits has a small influence on the efficiency of the index, the possibility to construct the total index without these traits 
TABLE 1: Reduction in the accuracy of the subindex, compared to the total index $\left(I_{T}\right)$, when individual or some criteria(s) were dropped from the index.

\begin{tabular}{lccccccccc}
\hline & \multirow{2}{*}{$I_{T}$} & $M$ & $F$ & $P$ & $F \%$ & $P \%$ & SCC & $F \%$ and $P \%$ & $F \%, P \%$, and SCC \\
\hline$r_{H I}^{2}$ & 0.911 & 0.517 & 0.533 & 0.529 & 0.893 & 0.907 & 0.868 & 0.835 & 0.871 \\
Reduction & - & 0.394 & 0.378 & 0.382 & 0.018 & 0.004 & 0.043 & 0.076 & 0.040
\end{tabular}

$I_{T}$ : total Index, $M$ : milk yield, $F$ : fat yield, $P$ : protein yield, $F \%$ : fat percent, $P \%$ : protein percent, SCC: somatic cell count, and $r_{H I}^{2}$ : index accuracy.

(criteria) was investigated. However, when criteria were dropped from the index, the index weights (coefficients) of the remaining criteria changed. For instance when $P \%$ or $F \%$ was dropped from the index the index weights ( $b$-values) for milk yield and SCC changed from positive to high negative value and from negative to high positive, value respectively, implying decreased milk yield and increased SCC, which is unacceptable. The same thing happened when $F \%$ and $P \%$ were both dropped at the same time from the index. It was, therefore, decided to retain the total index.

\section{Conclusion}

In this study, a detailed description of the development of a multitrait selection index was presented. Although this index was developed specifically for the Jersey cattle breed in Zimbabwe, the method employed can be used to develop indices for different breeds and different production systems within the same breed. The definition of the breeding objective and correlation structure between traits and criteria is necessary. Application of these principles and results is necessary if the dairy cattle industry is to maximise the exploitation of genetics and to improve its relative competitive position.

\section{Acknowledgment}

The authors thank Mr. N. B. Mware and his colleagues of Zimbabwe Livestock Identification Trust (LIT) for providing them with data that was used in this study.

\section{References}

[1] S. König and H. H. Swalve, "Application of selection index calculations to determine selection strategies in genomic breeding programs," Journal of Dairy Science, vol. 92, no. 10, pp. 52925303, 2009.

[2] J. F. Kluyts, F. W. C. Neser, and M. J. Bradfield, "Proposed economic selection indices for the Simmentaler breed in South Africa," South African Journal of Animal Sciences, vol. 37, no. 2, pp. 122-131, 2007.

[3] R. R. van der Westhuizen and J. van der Westhuizen, "A proposed selection index for feedlot profitability based on estimated breeding values," Genetics and Molecular Research, vol. 8, no. 2, pp. 448-455, 2009.

[4] J. C. M. Dekkers, "Prediction of response to marker-assisted and genomic selection using selection index theory," Journal of Animal Breeding and Genetics, vol. 124, no. 6, pp. 331-341, 2007.

[5] L. P. Sørensen, T. Mark, M. K. Sørensen, and S. Ostergaard, "Economic values and expected effect of selection index for pathogen-specific mastitis under Danish conditions," Journal of Dairy Science, vol. 93, no. 1, pp. 358-369, 2010.

[6] C. Sun, P. Madsen, M. S. Lund, Y. Zhang, U. S. Nielsen, and $\mathrm{G}$. Su, "Improvement in genetic evaluation of female fertility in dairy cattle using multiple-trait models including milk production traits," Journal of Animal Science, vol. 88, no. 3, pp. 871-878, 2010.

[7] B. J. Hayes, P. J. Bowman, A. J. Chamberlain, and M. E. Goddard, "Invited review: genomic selection in dairy cattle: progress and challenges," Journal of Dairy Science, vol. 92, no. 2, pp. 433-443, 2009.

[8] K. Kunaka and S. M. Makuza, "Genetic and environmental trends for milk traits for Zimbabwean Holstein-Friesian population," Pakistan Journal of Biological Sciences, vol. 8, no. 7, pp. 1011-1015, 2005.

[9] USDA, Agro-Climatic Zones in Zimbabwe, United States Department of Agriculture, Washington, DC, USA, 2009.

[10] E. M. Missanjo, Genetic and phenotypic evaluation of Zimbabwean Jersey cattle towards the development of a selection index [M.S. thesis], University of Zimbabwe, Harare, Zimbabwe, 2010.

[11] A. R. Gilmour, B. R. Cullis, S. J. Welham, and R. Thompson, ASReml Reference Manual, NSW Agriculture Biometrical Bulletin 3, New South Wales, Australia, 2002.

[12] M. J. M. Rutten, P. Bijma, J. A. Woolliams, and J. A. M. van Arendonk, "SelAction: software to predict selection response and rate of inbreeding in livestock breeding programs," Journal of Heredity, vol. 93, no. 6, pp. 456-458, 2002.

[13] D. S. Falconer and T. F. C. Mackay, Introduction to Quantitative Genetics, Longman Scientific and Technical, Essex, England, 4th edition, 1996.

[14] M. P. L. Calus, T. H. E. Meuwissen, A. P. W. de Roos, and R. F. Veerkamp, "Accuracy of genomic selection using different methods to define haplotypes," Genetics, vol. 178, no. 1, pp. 553$561,2008$. 

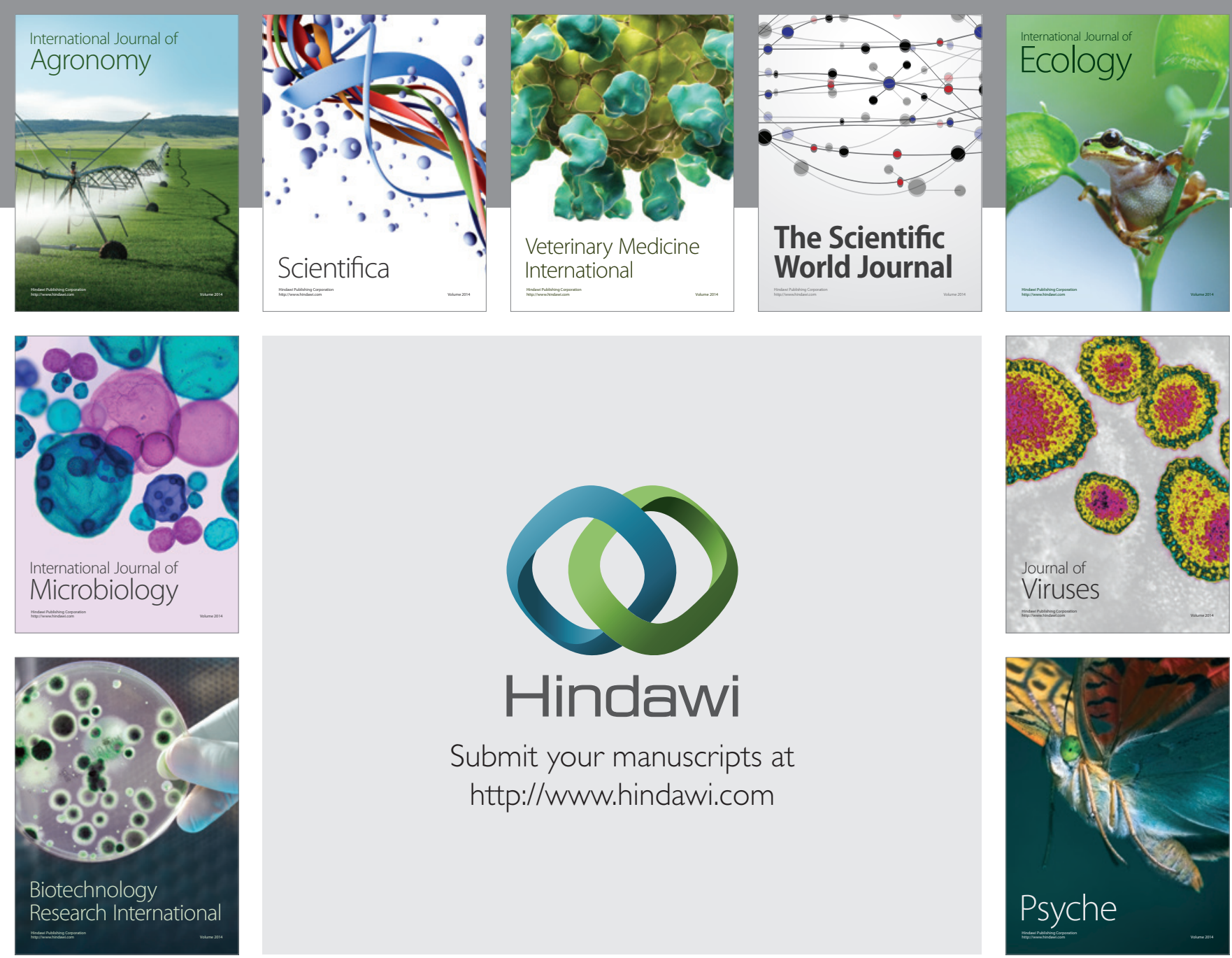

Submit your manuscripts at http://www.hindawi.com
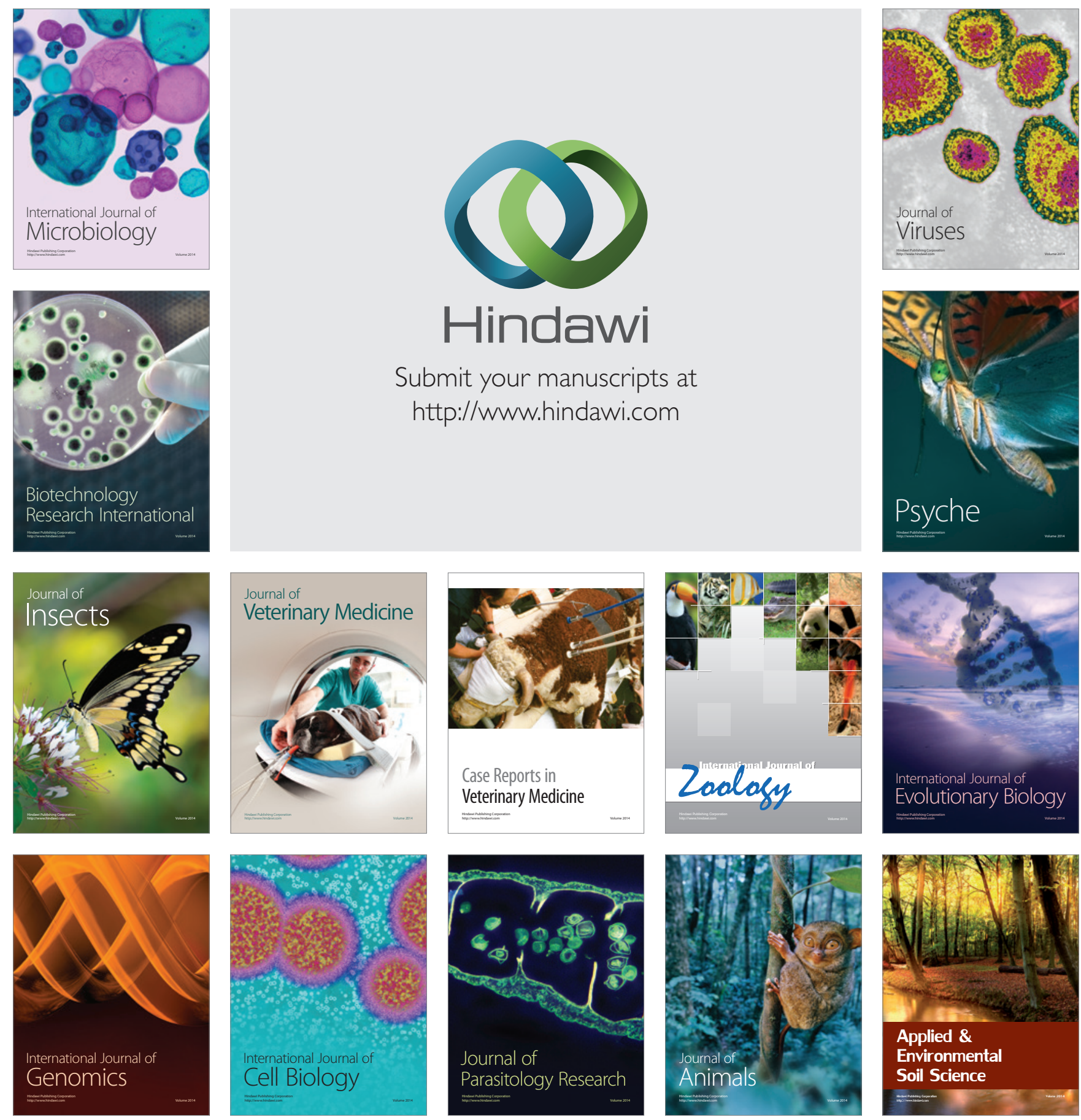